\title{
The aminoglycoside resistance methyltransferase Sgm impedes RsmF methylation at an adjacent rRNA nucleotide in the ribosomal $A$ site
}

\author{
SONJA ČUBRILO, ${ }^{1,2}$ FEDORA BABIĆ, ${ }^{2}$ STEPHEN DOUTHWAITE, ${ }^{1}$ and GORDANA MARAVIĆ VLAHOVIČEK ${ }^{2}$ \\ ${ }^{1}$ Department of Biochemistry and Molecular Biology, University of Southern Denmark, DK-5230 Odense, Denmark \\ ${ }^{2}$ Department of Biochemistry and Molecular Biology, Faculty of Pharmacy and Biochemistry, University of Zagreb, 10000 Zagreb, Croatia
}

\begin{abstract}
Ribosome-targeting antibiotics block protein synthesis by binding at functionally important regions of the bacterial rRNA. Resistance is often conferred by addition of a methyl group at the antibiotic binding site within an rRNA region that is already highly modified with several nucleotide methylations. In bacterial rRNA, each methylation requires its own specific methyltransferase enzyme, and this raises the question as to how an extra methyltransferase conferring antibiotic resistance can be accommodated and how it can gain access to its nucleotide target within a short and functionally crowded stretch of the rRNA sequence. Here, we show that the Sgm methyltransferase confers resistance to 4,6-disubstituted deoxystreptamine aminoglycosides by introducing the 165 rRNA modification $\mathrm{m}^{7} \mathrm{G} 1405$ within the ribosomal A site. This region of Escherichia coli $16 S$ rRNA already contains several methylated nucleotides including $m^{4} \mathrm{Cm} 1402$ and $\mathrm{m}^{5} \mathrm{C} 1407$. Modification at $\mathrm{m}^{5} \mathrm{C} 1407$ by the methyltransferase RsmF is impeded as Sgm gains access to its adjacent G1405 target on the 30S ribosomal subunit. An Sgm mutant (G135A), which is impaired in S-adenosylmethionine binding and confers lower resistance, is less able to interfere with RsmF methylation on the $30 \mathrm{~S}$ subunit. The two methylations at $16 \mathrm{~S}$ rRNA nucleotide $\mathrm{m}^{4} \mathrm{Cm} 1402$ are unaffected by both the wild-type and the mutant versions of Sgm. The data indicate that interplay between resistance methyltransferases and the cell's own indigenous methyltransferases can play an important role in determining resistance levels.
\end{abstract}

Keywords: aminoglycoside resistance; 16S rRNA methylation; Sgm; YebU (RsmF); RNA mass spectrometry

\section{INTRODUCTION}

The sisomicin-producing actinomycete Micromonospora zionensis protects its own ribosomes from the toxic effects of the aminoglycoside product by expression of the sisomicin-gentamicin resistance methyltransferase, Sgm (Kojic et al. 1992). Sgm confers resistance to 4,6-disubstituted deoxystreptamine aminoglycosides such as kanamycin, and thus functions similarly to its orthologs $\mathrm{KgmB}$ (Holmes and Cundliffe 1991), GrmA (Cundliffe 1992), and FmrO (Ohta and Hasegawa 1993) from other aminoglycoside-producing microorganisms, and also to ArmA (Galimand et al. 2003), RmtA (Yokoyama et al. 2003), RmtB (Doi et al. 2004), RmtC

Reprint requests to: Stephen Douthwaite, Department of Biochemistry and Molecular Biology, University of Southern Denmark, Campusvej 55, DK-5230 Odense M, Denmark; e-mail: srd@bmb.sdu.dk; fax: +45-65502467; or Gordana Maravić Vlahoviček, Department of Biochemistry and Molecular Biology, Faculty of Pharmacy and Biochemistry, University of Zagreb, Ante Kovačića 1, 10000 Zagreb, Croatia; e-mail: gordana@ pharma.hr; fax: +385-1-4856-201.

Article published online ahead of print. Article and publication date are at http://www.rnajournal.org/cgi/doi/10.1261/rna.1618809.
(Wachino et al. 2006), and RmtD (Doi et al. 2007) that have recently been identified in clinical strains. The methylation target of KgmB (Holmes and Cundliffe 1991), ArmA (Liou et al. 2006), and RmtB (Perichon et al. 2007) is the N7position of nucleotide G1405 in 16S rRNA (Escherichia coli numbering). Sgm is also thought to modify at G1405 (Holmes and Cundliffe 1991; Tomic et al. 2008), although this has not previously been verified experimentally. Nucleotide G1405 is located within a highly conserved and heavily modified rRNA region at the decoding site (A site) of the ribosome (Fig. 1). The 4,6-disubstituted deoxystreptamine aminoglycosides disrupt mRNA decoding by binding to this region through contact with nucleotide G1405 (Yoshizawa et al. 1998; Vicens and Westhof 2002). This contact is hindered by methylation of G1405 and results in drug resistance.

Drug resistance methylations in bacterial rRNAs, such as that at nucleotide G1405, have the sole function of providing protection against a specific group of antibiotics and offer no known physiological advantage in the absence of the drug. In this sense they contrast with the numerous 


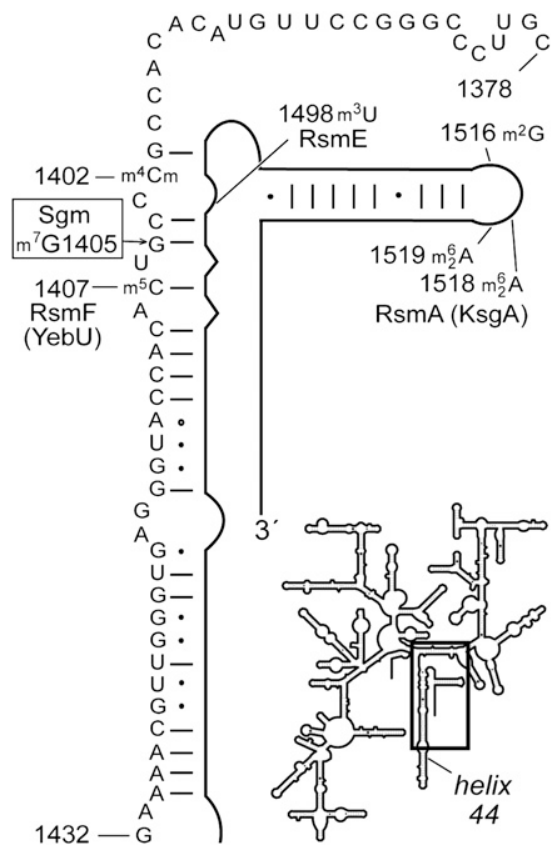

FIGURE 1. Representation of the $16 \mathrm{~S}$ rRNA secondary structure showing the sequence in helix 44 (boxed) that was isolated for analysis by mass spectrometry. The sites of post-transcriptional housekeeping modification in this E. coli rRNA region are indicated, and the methyltransferases that introduce these modifications are given (where known); the site of the $\mathrm{m}^{7} \mathrm{G} 1405$ modification added by the Sgm resistance methyltransferase is also shown.

indigenous methylations (also termed housekeeping methylations) that contribute to the overall structure and general function of the rRNA. In many other respects, however, the resistance and housekeeping methylations are similar in that they cluster in phylogenetically conserved and functionally essential regions of the rRNA, and each nucleotide methylation is introduced by its own distinct methyltransferase enzyme (Ofengand and Del Campo 2004; Andersen and Douthwaite 2006). At the ribosomal A site of E. coli 16S rRNA, several nucleotides including C1402, C1407, and U1498 (Fig. 1) are methylated by housekeeping methyltransferases. It seems that the interactions of these methyltransferases have evolved to be sterically compatible and/or temporally displaced such that each of the enzymes is able to gain access to and modify its own nucleotide target. This raises the question as to how well an additional methyltransferase modifying at nucleotide G1405 is accommodated in this functionally crowded region of the ribosome.

In this study, we have introduced a recombinant version of the Sgm methyltransferase gene into an E. coli strain that has a full complement of housekeeping methyltransferases. Analyses of the 16S rRNA by primer extension and MALDI mass spectrometry show that the $\mathrm{m}^{5} \mathrm{C} 1407$-specific housekeeping methyltransferase RsmF (previously termed YebU) is outcompeted by Sgm as the resistance methyltransferase gains access to its own $\mathrm{m}^{7} \mathrm{G} 1405$ target on the
30 S ribosomal subunit. A single amino acid change in Sgm, which lowers the level of conferred resistance, reduces the ability of Sgm to interfere with RsmF methylation on the $30 \mathrm{~S}$ subunit. The two housekeeping methylations at $16 \mathrm{~S}$ rRNA nucleotide $\mathrm{m}^{4} \mathrm{Cm} 1402$ are unaffected by both the wild-type and the mutant versions of Sgm.

\section{RESULTS AND DISCUSSION}

\section{Sgm modifies $m^{7} G 1405$ in $16 S$ rRNA}

We identified the site of Sgm methylation by two independent approaches. Total rRNA was extracted from ribosomal subunits isolated from E. coli cells harboring an expression vector encoding the sgm gene. In the first approach, sites of $\mathrm{m}^{7} \mathrm{G}$ methylation in the rRNAs were identified by borohydride/aniline treatment to induce $\beta$-elimination. Analysis of the rRNAs by primer extension with reverse transcriptase showed that one reverse transcriptase stop (Fig. 2) was dependent on Sgm and borohydride/aniline treatment and indicated that Sgm methylates at the N7position of nucleotide G1405.

Using a second approach, the $16 \mathrm{~S}$ rRNA sequence 1378 to 1432 (Fig. 1) was isolated by hybridization to a complementary deoxyoligonucleotide and the rest of the rRNA was removed with nucleases. The 1378-1432 sequence was then digested with RNase T1 and the fragments were analyzed by MALDI mass spectrometry. The rRNA from Sgm ${ }^{-}$ cells produced a distinct MS spectrum that included the two peaks at $m / z 1289$ and 3179, which correspond to the fragments C1402-G1405 and U1406-G1415, respectively (Fig. 3A).

After expression of the Sgm methyltransferase $\left(\mathrm{Sgm}^{+}\right.$ cells), the rRNA could no longer be cleaved at G1405 by RNase T1, resulting in the disappearance of the $m / z 1289$ and 3179 peaks (Fig. 3B) and the appearance of a new, larger peak at $m / z 4481$ (and at $m / z 4467$, see below). The

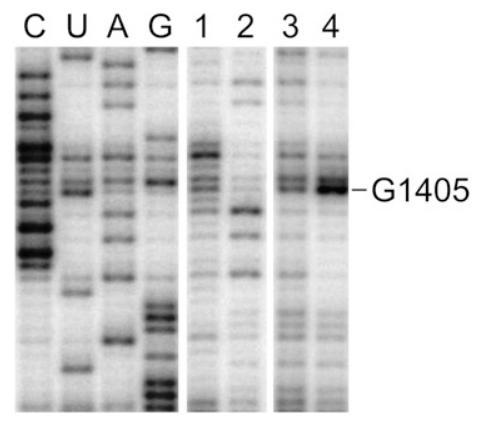

FIGURE 2. Gel autoradiogram of primer extension through the G1405 region of $16 \mathrm{~S}$ rRNA. The rRNAs were from E. coli cells without sgm (lanes 1,2) or from cells expressing wild-type sgm (lanes 3,4); samples were either untreated (lanes 1,3 ) or were treated with $\mathrm{NaBH}_{4} /$ aniline prior to primer extension. In lane 4, rRNA scission stops reverse transcriptase immediately $3^{\prime}$ to the site of Sgm methylation at G1405. 

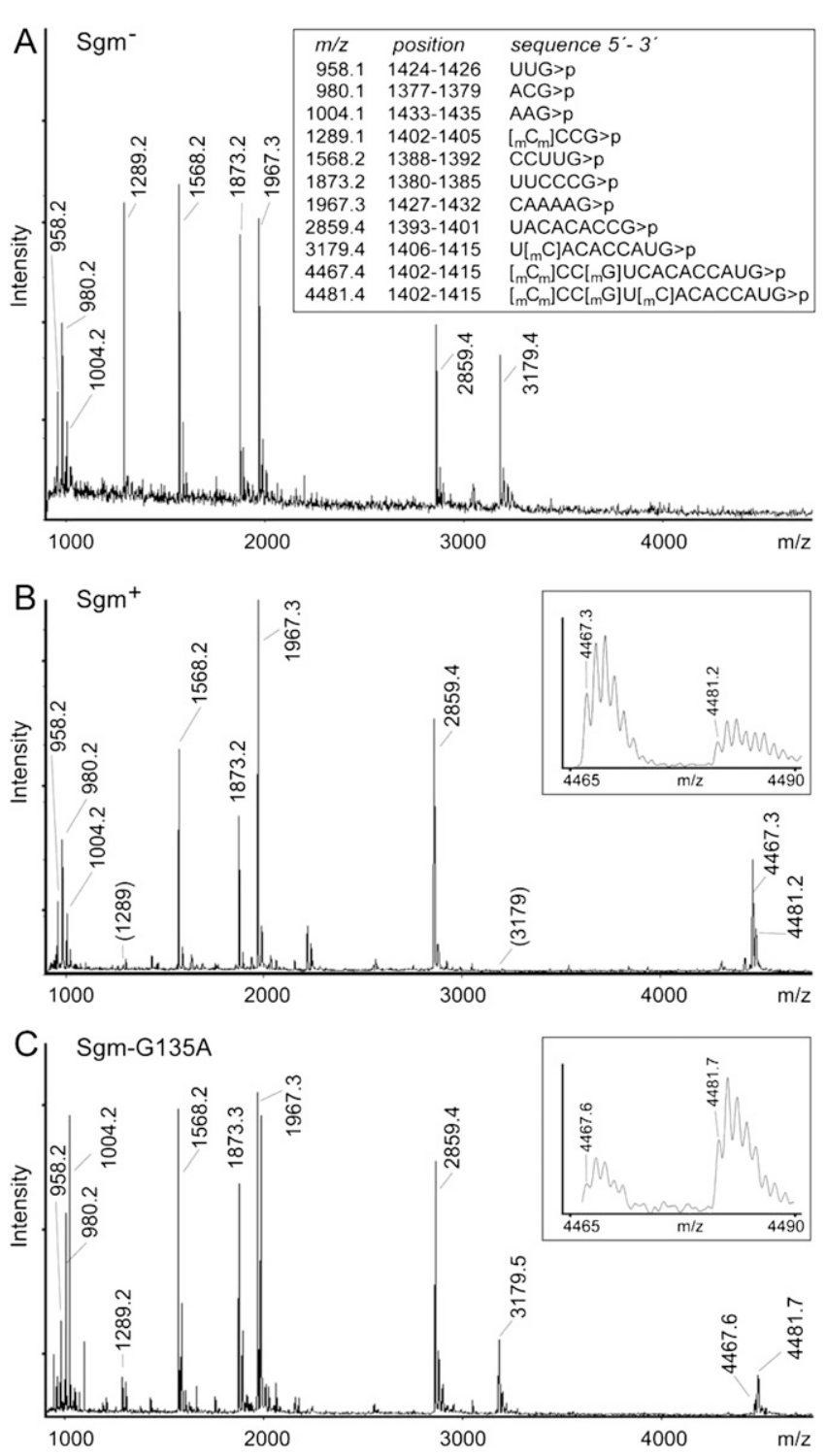

FIGURE 3. MALDI-MS spectra of RNase T1 oligonucleotides from the E. coli $16 \mathrm{~S}$ rRNA sequence C1378-G1432. (A) Spectrum of rRNA from cells without the sgm gene. The theoretical monoisotopic masses of the RNase digestion products with $3^{\prime}$-end cyclic phosphates $(>p)$ are shown in the box. Fragments smaller than trinucleotides are not shown. The theoretical and empirical masses (given above the peaks) match to within $0.2 \mathrm{Da}$. (B) The corresponding spectrum from $\mathrm{Sgm}^{+}$ cells showing that the fragments at $\mathrm{m} / z 1289$ and 3179 are missing and remain combined in the longer sequence at $\mathrm{m} / \mathrm{z} 4467$ and 4481. (Inset) Enlargement of this spectral region; the multiple tops in these fragments reflect the natural distribution of ${ }^{12} \mathrm{C}$ and ${ }^{13} \mathrm{C}$ isotopes. (C) The rRNA spectrum from Sgm-G135A cells; this differs from the $\mathrm{Sgm}^{+}$rRNA in the relative amplitudes of the $\mathrm{m} / \mathrm{z} 4467$ and 4481 peaks, and also peaks at $\mathrm{m} / \mathrm{z} 1289$ and 3179 are evident.

$m / z 4481$ peak corresponds to sequence C1402-G1415 in which the two smaller fragments remain combined and include an extra methyl group. The resistance to RNase T1 cleavage at nucleotide G1405 and the addition of $14 \mathrm{Da}$ extra mass clearly establish that Sgm methylates this nucleotide position. The complete loss of the $\mathrm{m} / z 1289$ and 3179 peaks from the spectrum (Fig. 3B) indicates that Sgm methylation at G1405 is stoichiometric.

In addition to the Sgm site at G1405, this sequence of the $16 \mathrm{~S}$ rRNA contains three housekeeping methylations (Fig. 1). Two of these modifications are at nucleotide $\mathrm{m}^{4} \mathrm{Cm} 1402$ and are added by presently uncharacterized methyltransferases; the third is at nucleotide $\mathrm{m}^{5} \mathrm{C} 1407$ and is added by the RsmF (formerly YebU) methyltransferase (Andersen and Douthwaite 2006). These methylations are evident in Figure $3 \mathrm{~A}$ as the $\mathrm{m} / z 1289$ peak (containing $\mathrm{m}^{4} \mathrm{Cm} 1402$ ) and the 3179 peak (containing $\mathrm{m}^{5} \mathrm{C} 1407$ ). The lack of unmodified fragments, which would run at $\mathrm{m} / \mathrm{z} 1261, \mathrm{~m} / \mathrm{z}$ 1275 , or $\mathrm{m} / \mathrm{z} 3165$ in the Figure 3A spectrum, indicates that $\mathrm{m}^{4} \mathrm{Cm} 1402$ and $\mathrm{m}^{5} \mathrm{C} 1407$ are normally stoichiometrically methylated in E. coli rRNA.

\section{Sgm reduces $\mathrm{RsmF}$ housekeeping methylation at $\mathbf{m}^{7} \mathrm{C} 1407$}

After expression of the Sgm methyltransferase, one of these housekeeping modifications is no longer stoichiometric; this is apparent from the presence of the $\mathrm{m} / \mathrm{z} 4467$ peak (containing three methyl groups) in addition to the $\mathrm{m} / \mathrm{z}$ 4481 peak (with four methyl groups). Tandem MS analysis of the $\mathrm{m} / \mathrm{z} 4467$ peak (not shown) showed that both methylations on nucleotide $\mathrm{m}^{4} \mathrm{Cm} 1402$ were present, and this fits with our previous observation that these methylations occur as a pair and have not been seen individually (Andersen and Douthwaite 2006). The $\mathrm{m}^{7} \mathrm{G} 1405$ modification must be present in the $m / z 4467$ peak to prevent its cleavage by RNase T1; thus, the rRNA is missing the RsmF methylation at C1407.

At a first glance, it might seem that the relative heights of the $m / z 4467$ and 4481 peaks indicate the extent to which RsmF methylation is suppressed by Sgm. However, any such quantitative interpretation of MALDI-MS data should be accompanied with a great deal of caution. The MALDI technique is notoriously inconsistent in the degree to which it ionizes molecules, and consequently the amplitudes of the resultant spectra signals are variable. This is illustrated in the heights of the $\mathrm{m} / \mathrm{z} 1004, \mathrm{~m} / \mathrm{z} 1568$, and $\mathrm{m} / \mathrm{z} 1967$ peaks corresponding to the AAG, CCUUG, and CAAAAG fragments. Despite the fact that these fragments are equimolar (as a consequence of being derived from the same RNA chain), they produce signals of different heights, and these relative heights vary from spectrum to spectrum (Fig. 3). That being said, our analyses of dozens of spectra for the $\mathrm{Sgm}^{+}$rRNA (as in Fig. 3B) showed that the heights of the $\mathrm{m} / z 4467$ and 4481 peaks were remarkably constant relative to each other (although not to the other spectral peaks). The consistency between the $\mathrm{m} / \mathrm{z} 4467$ and 4481 peaks undoubtedly reflects the near identical composition of the two ions, and, in this particular case, we believe that some guarded inferences can be made from the relative heights (see below). 
Sgm and RsmF recognize the same 30S subunit substrate

We determined the substrate that is recognized by Sgm by following the methylation reaction in vitro using purified histidine-tagged Sgm and a range of potential substrates including $70 S$ ribosomes, separated $30 \mathrm{~S}$ and $50 \mathrm{~S}$ subunits, and naked $16 \mathrm{~S}$ rRNA. The methylation reaction was monitored by the incorporation of radiolabeled S-adenosylmethionine into the rRNA (Table 1). Sgm methylation is dependent on the presence of the S-adenosylmethionine cofactor, and only the $30 \mathrm{~S}$ ribosomal subunit functions as a valid substrate. In vitro methylation of $30 \mathrm{~S}$ subunits at nucleotide G1405 was confirmed in parallel MS experiments using nonlabeled cofactor (not shown). Substrate recognition by Sgm is therefore similar to that of RsmF, which also uses $30 \mathrm{~S}$ subunits as its substrate and is unable to modify naked 16S rRNA or 70 S ribosomes (Andersen and Douthwaite 2006). Docking simulations with the RsmF crystal structure indicate contact with ribosomal components including r-protein S12 at the interface of the 30S subunit; in the 70S ribosome, access of the methyltransferase to these contact sites is blocked by the $50 \mathrm{~S}$ subunit (Hallberg et al. 2006).

\section{Sgm activity affects its ability to hinder C1407 methylation by RsmF}

The in vitro methylation studies indicate that Sgm and RsmF attempt to gain access to the same region of the $16 \mathrm{~S}$ rRNA and at the same time-immediately after (and possibly during) $30 \mathrm{~S}$ subunit assembly, but before association with the 50S subunit. The apparent competition between the two methyltransferases was studied further in vivo using a Sgm variant with impaired enzymatic activity. Several Sgm mutants have previously been shown to confer greatly reduced aminoglycoside resistance (Maravić Vlahoviček et al. 2008; Savic et al. 2008). We chose a representative mutant, Sgm-G135A, which is a poor binder of

TABLE 1. Methylation in vitro by the recombinant, wild-type Sgm enzyme

\begin{tabular}{|c|c|c|}
\hline \multirow[b]{2}{*}{ Substrate } & \multicolumn{2}{|c|}{$\begin{array}{c}\text { Incorporation } \\
\text { of }\left[{ }^{3} \mathrm{H}\right] \text {-methyl groups } \\
(\mathrm{cpm})\end{array}$} \\
\hline & No enzyme & Sgm \\
\hline $70 \mathrm{~S}$ ribosomes & $13.0 \pm 4.6$ & $37.4 \pm 22.4$ \\
\hline $30 S$ ribosomal subunits & $10.6 \pm 1.1$ & $278.2 \pm 23.8$ \\
\hline $50 S$ ribosomal subunits & $13.9 \pm 1.1$ & $12.5 \pm 0.5$ \\
\hline Total rRNA & $12.7 \pm 2.5$ & $13.4 \pm 3.0$ \\
\hline \multicolumn{3}{|c|}{$\begin{array}{l}\text { Significant retention of }{ }^{3} \mathrm{H} \text {-labeled methyl groups was observed } \\
\text { only when } 30 \mathrm{~S} \text { subunits were used as the substrate (bold); this } \\
\text { corresponds to the incorporation of } 0.52 \pm 0.04 \text { mol of methyl } \\
\text { groups per mole of } 30 \mathrm{~S} \text { subunits. The slightly elevated value and } \\
\text { large standard deviation for } 70 \mathrm{~S} \text { ribosomes is thought to reflect } \\
\text { partial dissociation of the subunits in some samples. }\end{array}$} \\
\hline
\end{tabular}

the S-adenosylmethionine cofactor (Savic et al. 2008), to determine whether the resistance level correlates with a reduced ability to methylate at the G1405 and to compete with RsmF. In E. coli, this mutant enzyme confers resistance to kanamycin at up to $32 \mu \mathrm{g} / \mathrm{mL}$, compared with resistance at $>1280 \mu \mathrm{g} / \mathrm{mL}$ for E. coli expressing wild-type Sgm, and $<1 \mu \mathrm{g} / \mathrm{mL}$ for Sgm ${ }^{-}$cells (Maravić Vlahoviček et al. 2008).

The methylation pattern of the 16S rRNA from cells with Sgm-G135A was analyzed by MALDI-MS (Fig. 3C). The spectral peaks at $m / z 4467$ and 4481 show that the SgmG135A mutant is still capable of methylating G1405; however, the reappearance of the $\mathrm{m} / z 1289$ and $\mathrm{m} / \mathrm{z} 3179$ peaks indicates that G1405 methylation is no longer complete. There is no peak at $m / z$ 1365, and therefore all the rRNA molecules are methylated at C1407 and/or G1405. The molecules left unmethylated by RsmF congregate exclusively in the $m / z 4467$ peak, which is now reproducibly smaller than the $m / z 4481$ peak (Fig. 3C). Thus, the impaired cofactor binding of Sgm-G135A reduces its efficiency in methylating the G1405 target, which in turn enables RsmF to partially re-establish its claim to the region and methylate at nucleotide C1407.

Modeling of the Sgm structure (Maravić Vlahoviček et al. 2008) and of RsmF on the 30 S subunit (Hallberg et al. 2006) is consistent with a mechanism whereby the bulky methyltransferases sterically clash in their attempts to gain access to their respective targets at G1405 and C1407. In this scenario, the wild-type Sgm interacts more effectively with the $30 \mathrm{~S}$ subunit and physically obstructs the binding of RsmF; this advantage of Sgm is then markedly reduced when the G135A mutation lowers its activity. It should be noted, however, that our observations fit equally well with an alternative explanation where modification at $\mathrm{m}^{7} \mathrm{G} 1405$ obscures an essential element for RsmF recognition and, in this model, inhibition would persist after Sgm has dissociated from the substrate.

\section{Interference between methyltransferases and variance in resistance levels}

The rRNA target sites of resistance methyltransferases tend to be close to those of the indigenous housekeeping modifications. Loss of an individual housekeeping modification generally has a measurable fitness cost, although this is often quite small. In the case of RsmF, the growth rate of E. coli is reduced by $\sim 20 \%$ after loss of $\mathrm{m}^{5} \mathrm{C} 1407$ methylation (Andersen and Douthwaite 2006). In E. coli, the consequences of Sgm affecting RsmF function and cell fitness would naturally be offset in the presence of aminoglycoside antibiotics, although it might be expected that there would be a selection against methyltransferases such as Sgm in the absence of antibiotics.

Sgm has evolved as a natural component in its actinomycete host, Micromonospora zionensis, and as such it would not be expected to clash with other indigenous 
methyltransferase. In fact, no ortholog of $r s m F$ is apparent in any actinomycete genome that has been sequenced to date. We have analyzed the rRNA from three actinomycetes: Mycobacterium smegmatis, Mycobacterium tuberculosis (Johansen et al. 2006), and Streptomyces coelicolor (S Johansen and S Douthwaite, unpubl.) by MALDI-MS, and all lack modification at $16 \mathrm{~S}$ rRNA nucleotide C1407. Although the genome and rRNAs from $M$. zionensis have not yet been analyzed, it seems unlikely based on the available evidence that this species possesses an RsmF homolog.

Competition in accessing rRNA targets is presumably by no means limited to RsmF and Sgm, and might involve the nearby modification at nucleotide U1498 (Basturea et al. 2006), or C1404 in thermophiles (Guymon et al. 2006), or C1409 and G1410 in mycobacterial actinomycetes (Johansen et al. 2006). Other G1405 methyltransferases would presumably also clash with housekeeping modification enzymes, and the outcome of these confrontations might explain why, despite modifying the same site, they do not always confer identical resistance phenotypes. For instance, the resistance conferred by the G1405 methyltransferases RmtC (Wachino et al. 2006) and RmtA (Yokoyama et al. 2003) appears particularly potent. Differences in resistance phenotypes can be due to many factors, although one aspect that until now has been overlooked is how effectively a resistance methyltransferase that has been acquired as an exogenous genetic element can elbow aside the cell's own housekeeping methyltransferases to gain access to its target.

\section{MATERIALS AND METHODS}

\section{Strains and plasmids}

The $s g m$ gene was expressed from the plasmid vector pET-25b(+) in E. coli C41(DE3) and purified as described previously (Maravić Vlahoviček et al. 2008). Mutations including G135A were introduced into sgm based on the tertiary structure predictions for the methyltransferase (Maravić Vlahoviček et al. 2008). Measurements of resistance levels expressed as minimal inhibitory concentrations of kanamycin (Sigma) were described previously (Maravić Vlahoviček et al. 2008).

\section{Analysis of rRNA by primer extension}

Total rRNA was extracted from ribosomal particles isolated from E. coli C41(DE3) cells harboring the expression vector pET-25b(+) with and without recombinant versions of the sgm gene. Cells were grown in the presence of $1 \mathrm{mM}$ IPTG and were harvested in early $\log$ phase at an $\mathrm{OD}_{450}$ of $0.4-0.5$. Sites of $\mathrm{m}^{7} \mathrm{G}$ methylation in the rRNAs were reduced with sodium borohydride $\left(\mathrm{NaBH}_{4}\right)$ and cleaved via aniline-induced $\beta$-elimination (Peattie 1979). This reaction is generally incomplete (Douthwaite et al. 1983) but was improved by inclusion of hypermethylated tRNA carrier in the reactions (Zueva et al. 1985). A 5'-32 P-end-labeled deoxynucleotide primer, complementary to $16 \mathrm{~S}$ rRNA nucleotides 1459-1479, was hybridized to the rRNA and extended with AMV reverse transcriptase (Finnzymes) (Stern et al. 1988). Sequencing reac- tions were preformed on rRNA from the E. coli cells lacking Sgm. Extension products were separated on denaturing polyacrylamide gels and were visualized by phosphorimaging (Typhoon, Amersham Biosciences).

\section{Analysis of rRNA by MALDI mass spectrometry}

The 16S rRNA sequence from C1378-G1432 was isolated by hybridization to complementary deoxyoligonucleotides, and $40 \mathrm{pmol}$ of rRNA were heated with 400 pmol of deoxyoligonucleotide (complementary to the sequence shown in Fig. 1) for $1 \mathrm{~min}$ at $85^{\circ} \mathrm{C}$, followed by slow cooling over $2 \mathrm{~h}$ to $45^{\circ} \mathrm{C}$. Unhybridized regions of the rRNAs were digested with mung bean nuclease (NE Biolabs) and RNase A (Sigma), and the rRNA fragment protected by the deoxyoligonucleotide was isolated by gel electrophoresis (Andersen et al. 2004). The rRNA fragment was digested with 20 units of RNase T1 (Ambion) for $3 \mathrm{~h}$ at $37^{\circ} \mathrm{C}$ in $2 \mu \mathrm{L}$ of $\mathrm{H}_{2} \mathrm{O}$ containing $0.25 \mu \mathrm{L}$ of $0.5 \mathrm{M}$ 3-hydroxypicolinic acid. Samples were dried and resuspended in $1 \mu \mathrm{L}$ of $\mathrm{H}_{2} \mathrm{O}$ prior to analysis by MALDI-MS (Voyager Elite, Perseptive Biosystems) recording in reflector and positive ion mode (Kirpekar et al. 2000). Spectra were analyzed using the program $\mathrm{m} / \mathrm{z}$ (Proteometrics, Inc).

\section{In vitro methylation reactions}

Ribosome 70 S couples, separated $30 \mathrm{~S}$ and $50 \mathrm{~S}$ subunits, and naked rRNAs were tested as substrates for Sgm-mediated methylation. Reactions for in vitro methylation contained 5 pmol of substrate and 1 pmol of Sgm enzyme with a mixture of 2 nmol of nonradioactive AdoMet (Sigma) and 1 pmol of [methyl $-{ }^{3} \mathrm{H}$ ] AdoMet (82 $\mathrm{Ci} / \mathrm{mmol}$, Amersham Biosciences/GE Healthcare) as the methyl donor. All reactions were carried out at $37^{\circ} \mathrm{C}$ in $100 \mu \mathrm{L}$ of $20 \mathrm{mM}$ Tris, pH 7.5, $40 \mathrm{mM} \mathrm{NH}_{4} \mathrm{Cl}, 7.5 \mathrm{mM} \mathrm{MgCl}_{2}, 6 \mathrm{mM}$ $\beta$-mercaptoethanol with $10 \%$ glycerol. Reactions were stopped by the addition of $10 \%(\mathrm{w} / \mathrm{v})$ trichloroacetic acid, and the precipitated substrates were pelleted by centrifugation and counted for radioactivity. In control experiments, the Sgm enzyme and the substrates were incubated separately with AdoMet. Duplicate samples were measured in three independent experiments in all cases.

\section{ACKNOWLEDGMENTS}

We thank Anette Rasmussen and Finn Kirpekar (University of Southern Denmark) for invaluable help with the collection and interpretation of the MALDI data. G.M.V. thanks the Croatian Ministry of Science (grant 006-0982913-1219), ICGEB (grant CRP/CRO08-02), and FP6 (grant \#043682 "EuroPharm" as support to F.B.) for support. S.D. thanks the Danish Research Agency (FNU-rammebevilling 272-07-0613), the Nucleic Acid Center of the Danish Grundforskningsfond, and NAC-DRUG under the FP6 Marie Curie Initial Training Networks (to S.Č.) for support.

Received February 25, 2009; accepted May 1, 2009.

\section{REFERENCES}

Andersen NM, Douthwaite S. 2006. YebU is a $\mathrm{m}^{5} \mathrm{C}$ methyltransferase specific for 16S rRNA nucleotide 1407. J Mol Biol 359: 777786. 
Andersen TE, Porse BT, Kirpekar F. 2004. A novel partial modification at C2501 in Escherichia coli $23 \mathrm{~S}$ ribosomal RNA. RNA 10: 907-913.

Basturea GN, Rudd KE, Deutscher MP. 2006. Identification and characterization of RsmE, the founding member of a new RNA base methyltransferase family. RNA 12: 426-434.

Cundliffe E. 1992. Resistance to macrolides and lincosamides in Streptomyces lividans and to aminoglycosides in Micromonospora purpurea. Gene 115: 75-84.

Doi Y, Yokoyama K, Yamane K, Wachino J, Shibata N, Yagi T, Shibayama K, Kato H, Arakawa Y. 2004. Plasmid-mediated 16S rRNA methylase in Serratia marcescens conferring high-level resistance to aminoglycosides. Antimicrob Agents Chemother 48: 491-496.

Doi Y, de Oliveira Garcia D, Adams J, Paterson DL. 2007. Coproduction of novel 16S rRNA methylase RmtD and metallo$\beta$-lactamase SPM-1 in a panresistant Pseudomonas aeruginosa isolate from Brazil. Antimicrob Agents Chemother 51: 852-856.

Douthwaite S, Garrett RA, Wagner R. 1983. Comparison of Escherichia coli RNA $^{\text {Phe }}$ in the free state, in the ternary complex and in the ribosomal A and P sites by chemical probing. Eur J Biochem 131: $261-269$.

Galimand M, Courvalin P, Lambert T. 2003. Plasmid-mediated highlevel resistance to aminoglycosides in Enterobacteriaceae due to 16S rRNA methylation. Antimicrob Agents Chemother 47: 2565-2571.

Guymon R, Pomerantz SC, Crain PF, McCloskey JA. 2006. Influence of phylogeny on posttranscriptional modification of rRNA in thermophilic prokaryotes: The complete modification map of $16 \mathrm{~S}$ rRNA of Thermus thermophilus. Biochemistry 45: 4888-4899.

Hallberg BM, Ericsson UB, Johnson KA, Andersen NM, Douthwaite S, Nordlund P, Beuscher AE, Erlandsen H. 2006. The structure of the RNA $\mathrm{m}^{5} \mathrm{C}$ methyltransferase YebU from Escherichia coli reveals a C-terminal RNA-recruiting PUA domain. J Mol Biol 360: 774-787.

Holmes DJ, Cundliffe E. 1991. Analysis of a ribosomal RNA methylase gene from Streptomyces tenebrarius which confers resistance to gentamicin. Mol Gen Genet 229: 229-237.

Johansen SK, Maus CE, Plikaytis BB, Douthwaite S. 2006. Capreomycin binds across the ribosomal subunit interface using tlyAencoded 2'-O-methylations in $16 \mathrm{~S}$ and $23 \mathrm{~S}$ rRNAs. Mol Cell 23: $173-182$.

Kirpekar F, Douthwaite S, Roepstorff P. 2000. Mapping posttranscriptional modifications in $5 \mathrm{~S}$ ribosomal RNA by MALDI mass spectrometry. RNA 6: 296-306.

Kojic M, Topisirovic L, Vasiljevic B. 1992. Cloning and characterization of an aminoglycoside resistance determinant from Micromonospora zionensis. J Bacteriol 174: 7868-7872.

Liou GF, Yoshizawa S, Courvalin P, Galimand M. 2006. Aminoglycoside resistance by ArmA-mediated ribosomal 16S methylation in human bacterial pathogens. J Mol Biol 359: 358-364.
Maravić Vlahoviček G, Čubrilo S, Tkaczuk KL, Bujnicki JM. 2008. Modeling and experimental analyses reveal a two-domain structure and amino acids important for the activity of aminoglycoside resistance methyltransferase Sgm. Biochim Biophys Acta 1784, 582590.

Ofengand J, Del Campo M. 2004. Modified nucleosides in Escherichia coli ribosomal RNA. In EcoSal-Escherichia coli and Salmonella: Cellular and molecular biology (ed. R Curtiss). ASM Press, Washington, DC.

Ohta T, Hasegawa M. 1993. Analysis of the self-defense gene ( $\mathrm{mrO}$ ) of a fortimicin A (astromicin) producer, Micromonospora olivasterospora: Comparison with other aminoglycoside-resistanceencoding genes. Gene 127: 63-69.

Peattie DA. 1979. Direct chemical method for sequencing RNA. Proc Natl Acad Sci 76: 1760-1764.

Perichon B, Courvalin P, Galimand M. 2007. Transferable resistance to aminoglycosides by methylation of G1405 in 16S rRNA and to hydrophilic fluoroquinolones by QepA-mediated efflux in Escherichia coli. Antimicrob Agents Chemother 51: 2464-2469.

Savic M, Ilic-Tomic T, Macmaster R, Vasiljevic B, Conn GL. 2008. Critical residues for cofactor binding and catalytic activity in the aminoglycoside resistance methyltransferase Sgm. J Bacteriol 190: 5855-5861.

Stern S, Moazed D, Noller HF. 1988. Structural analysis of RNA using chemical and enzymatic probing monitored by primer extension. Methods Enzymol 164: 481-489.

Tomic TI, Moric I, Conn GL, Vasiljevic B. 2008. Aminoglycoside resistance genes $\mathrm{sgm}$ and $\mathrm{kgmB}$ protect bacterial but not yeast small ribosomal subunits in vitro despite high conservation of the rRNA A-site. Res Microbiol 159: 658-662.

Vicens Q, Westhof E. 2002. Crystal structure of a complex between the aminoglycoside tobramycin and an oligonucleotide containing the ribosomal decoding a site. Chem Biol 9: 747-755.

Wachino J, Yamane K, Shibayama K, Kurokawa H, Shibata N, Suzuki S, Doi Y, Kimura K, Ike Y, Arakawa Y. 2006. Novel plasmid-mediated $16 \mathrm{~S}$ rRNA methylase, RmtC, found in a Proteus mirabilis isolate demonstrating extraordinary high-level resistance against various aminoglycosides. Antimicrob Agents Chemother 50: $178-184$.

Yokoyama K, Doi Y, Yamane K, Kurokawa H, Shibata N, Shibayama K, Yagi T, Kato H, Arakawa Y. 2003. Acquisition of $16 \mathrm{~S}$ rRNA methylase gene in Pseudomonas aeruginosa. Lancet 362: $1888-1893$.

Yoshizawa S, Fourmy D, Puglisi JD. 1998. Structural origins of gentamicin antibiotic action. EMBO J 17: 6437-6448.

Zueva VS, Mankin AS, Bogdanov AA, Baratova LA. 1985. Specific fragmentation of tRNA and rRNA at a 7-methylguanine residue in the presence of methylated carrier RNA. Eur J Biochem 146: 679687. 

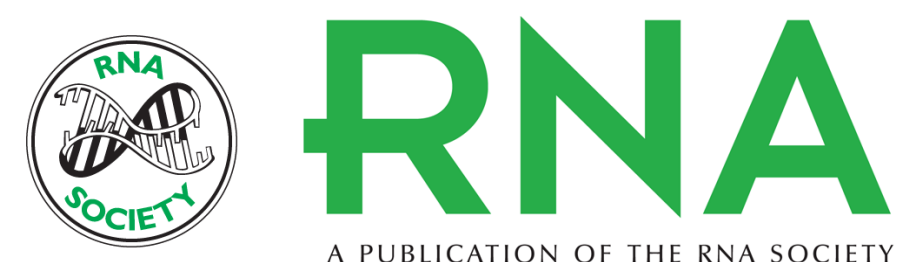

A PUBLICATION OF THE RNA SOCIETY

\section{The aminoglycoside resistance methyltransferase Sgm impedes RsmF methylation at an adjacent rRNA nucleotide in the ribosomal A site}

Sonja Cubrilo, Fedora Babic, Stephen Douthwaite, et al.

RNA 2009 15: 1492-1497 originally published online June 9, 2009

Access the most recent version at doi:10.1261/rna.1618809

$\begin{array}{ll}\text { References } & \begin{array}{l}\text { This article cites } 27 \text { articles, } 12 \text { of which can be accessed free at: } \\ \text { http://rnajournal.cshlp.org/content/15/8/1492.full.html\#ref-list-1 }\end{array}\end{array}$

License

Email Alerting Receive free email alerts when new articles cite this article - sign up in the box at the Service top right corner of the article or click here.

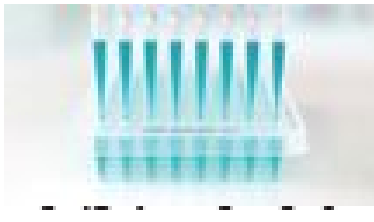

Providing Precise Solutions for your research.

To subscribe to RNA go to:

http://rnajournal.cshlp.org/subscriptions 